\title{
Aprendizagem flexível como o novo princípio educativo para a classe trabalhadora
}

\author{
Taise Cristina Gomes Clementino de \\ Negreiros $^{1}$ \\ https://orcid.org/0000-0002-4404-2398 \\ Angela Santana do Amaral ${ }^{2}$ \\ https://orcid.org/0000-0003-2038-1296 \\ ${ }^{1}$ Universidade de Brasília, Departamento de Serviço Social, Brasília, DF, Brasil \\ ${ }^{2}$ Universidade Federal de Pernambuco, Departamento de Serviço Social, Programa de Pós-Graduação em Serviço Social, \\ Recife, PE, Brasil
}

\begin{abstract}
Aprendizagem flexível como o novo princípio educativo para a classe trabalhadora
Resumo: O artigo analisa o desenvolvimento e uso das Tecnologias da Informação e Comunicação (TICs) na sociedade capitalista, a partir do segundo decênio dos anos 2000, com o objetivo de revelar o projeto de formação profissional para a classe trabalhadora. Amparado em uma perspectiva socio-histórica, recorreu à análise bibliográfica e documental para identificar, nos principais aparelhos privados de hegemonia, as diretrizes das políticas educacionais contemporâneas e evidenciar os mecanismos político-ideológicos que reconfiguram as experiências de formação mediadas pelas TICs. Os resultados expõem o contexto de expansão do uso das tecnologias de informação e comunicação nos marcos do desemprego, da flexibilização, desregulamentação do trabalho e do fenômeno da uberização. Revelam as estratégias de adequação do trabalhador à sociabilidade capitalista, com destaque para a formação de habilidades genéricas e competências socioemocionais, as quais incidem no campo didático-pedagógico, conformando-o em espaço de acumulação e reprodução do capital.
\end{abstract}

Palavras-chave: Tecnologias da Informação e Comunicação. Educação. Aprendizagem flexível. Classe Trabalhadora.

\section{Flexible learning as the new educational principle for the working classe}

Abstract: The article analyzes the development and use of Information and Communication Technologies (ICTc) in capitalist society, from the second decade of the 2000s onwards, with the aim of revealing the professional training project for the working class. Supported by a socio-historical perspective, it resorted to bibliographical and documental analysis to identify, in the main private apparatuses of hegemony, the guidelines of contemporary educational policy and highlight the political-ideological mechanisms that reconfigure the training experiences mediated by ICTs. The results expose the context of the expansion of the use of information and communication technologies in the context of unemployment, flexibilization, deregulation of work and the phenomenon of uberization. They reveal the worker's adaptation strategies to capitalist sociability, with emphasis on the formation of generic skills and socio-emotional competences, which affect the didactic-pedagogical field, making it a space for capital accumulation and reproduction.

Keywords: Information and communication technologies. Education. Flexible learning. Working class

Recebido em 02.03.2021. Aprovado em 06.05.2021. Revisado em 14.06.2021.

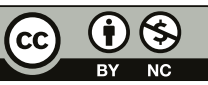

Este é um artigo publicado em acesso aberto (Open Access) sob a licença Creative Commons Attribution NonCommercial, que permite uso, distribuição e reprodução em qualquer meio, sem restrições desde que sem fins comerciais e que o trabalho original seja corretamente citado. 


\section{Introdução}

Na segunda metade dos anos 2000, constatamos o avanço de novas tecnologias de informação e comunicação, da Inteligência Artificial (IA) e dos recursos da internet nas empresas capitalistas, abrindo possibilidades, a partir dos recursos digitais, de o capital avançar nas suas estratégias de reduzir trabalho vivo, potencializando suas taxas de lucro através da incorporação da ciência e tecnologia. Esse fenômeno se efetiva em nível global e se espraia em diversos campos da gestão, do controle e da supervisão dos processos produtivos.

Essa nova configuração industrial denominada por indústria 4.0 (ANTUNES, 2018) tem sido estudada a partir do debate sobre a substituição do trabalho vivo pelo trabalho morto, a ampliação da superpopulação relativa e o aprofundamento da precarização das condições de vida da classe trabalhadora. Como afirma o autor, o que se evidencia é um tempo do não trabalho, do trabalho intermitente, ou seja, um contexto no qual a classe trabalhadora tende a se submeter a condições de trabalho cada vez mais instáveis, sem amparo de direitos trabalhistas e vínculos empregatícios formais.

É nesse cenário que presenciamos, especialmente no campo da formação profissional, a defesa de uma radical reformulação nos processos educativos da classe trabalhadora, por parte de intelectuais do capital e aparelhos privados de hegemonia ${ }^{1}$. Essa perspectiva, nominada de aprendizagem flexível, é orientada, prioritariamente, pela mediação das Tecnologias de Informação e Comunicação (TICs), e objetiva possibilitar ao educando o desenvolvimento de habilidades e competências necessárias a uma melhor adequação ao mercado de trabalho e à nova dinâmica laboral requerida no mundo capitalista.

É incontestável que o desenvolvimento dos recursos tecnológicos — sobretudo a partir dos anos 2000, com o avanço no campo da programação computacional e da telefonia móvel — ampliou as formas de acesso ao conhecimento e possibilitou a utilização de novos recursos didático-pedagógicos no processo de ensinoaprendizagem.

Contudo, precisamos compreender como essas tecnologias são incorporadas nos processos formativos de uma sociabilidade que é estruturalmente desigual. $\mathrm{O}$ acesso à educação e ao conhecimento socialmente produzido não ocorre, nos marcos do capitalismo, de forma homogênea entre todos os indivíduos. É determinado pelo dualismo educacional que é inerente à sociedade burguesa e, portanto, está intrinsecamente relacionado ao antagonismo de classes e conflitos de interesses que estão presentes no sistema educacional.

Diante dos avanços dos recursos tecnológicos e informacionais, um novo perfil de trabalhador é exigido: há que ser mais colaborativo, participativo, flexível e com atributos de resolução de problemas de forma autônoma e criativa, uma vez que as atividades burocráticas e repetitivas, nos argumentos dominantes, tendem a ser não mais executadas pela força de trabalho humana, mas por computadores e máquinas inteligentes.

O cenário da pandemia da Covid-19 acelerou as respostas capitalistas às suas crises. Daí que as TICs ganharam força no âmbito dos serviços e dos sistemas educacionais, expandindo novos negócios e segmentos produtivos. Passamos a conviver, de modo mais sistemático, com as plataformas digitais, com o teletrabalho, com o ensino remoto e com novos produtos de caráter inovador que conformam novos nichos de expansão e acumulação de capital.

\section{O acirramento da crise socioeconômica e as estratégias burguesas para a formação da classe trabalhadora}

O redirecionamento das práticas educativas perpassou todo o processo histórico de emergência e consolidação do modo de produção capitalista, como estratégia de recomposição do domínio hegemônico burguês, sobretudo em contexto de crise.

Situamos os anos 80 do século passado como marco da aceleração de novos mecanismos de disciplinamento da força de trabalho, de modo a adequá-la a uma conjuntura na qual o processo de destruição e reconstrução de habilidades se torna fundamental para as novas demandas de acumulação capitalista. Nesse sentido, fez-se necessário formar trabalhadores flexíveis que acompanham as mudanças decorrentes da matriz tecnológica e científica contemporânea e sejam capazes de desenvolver qualidades subjetivas compatíveis com a racionalidade do trabalho flexível, instável e precarizado, predominante em escala planetária. 
A mediação do uso de novas tecnologias através do vertiginoso desenvolvimento da microeletrônica se expandiu para as diversas instâncias da vida social e foi decisiva para a instauração de uma nova e complexa dinâmica no âmbito das relações sociais. Nas últimas três décadas do século XX, o capital passou por uma reestruturação do seu processo produtivo e reprodutivo, o que demarcou um novo rumo para o sistema capitalista como sistema sociometabólico (MÉSZÁROS, 2011). Nesse período, o conjunto de mudanças no âmbito da produção e da reprodução social produziu renovadas estratégias de superação da crise permanente do capital, buscando na intensificação das condições de exploração da força de trabalho a combinação das formas relativa e absoluta de extração de mais-valia.

Conforme assinala Harvey (2017, p. 140), esta conjuntura "caracteriza-se pelo surgimento de setores de produção inteiramente novos, novas maneiras de fornecimento de serviços financeiros, novos mercados e, sobretudo, taxas altamente intensificadas de inovação comercial, tecnológica e organizacional".

Outra tendência da denominada acumulação flexível é a ampliação dos instrumentos financeiros como uma das principais estratégias para o capital garantir sua reprodução cada vez mais ampliada e mundializada. Esses instrumentos foram viabilizados tanto pelas potencialidades que o avanço das TICs proporcionou (a exemplo da superação de limites geográficos, cronológicos e operacionais) quanto pela intervenção estatal em processos de liberalização e desregulamentação de mercados na busca de campos de investimento de capitais superacumulados e que necessitavam de valorização.

A expansão da financeirização da economia provocou um deslocamento de capitais da esfera da produção para o mercado financeiro, e a aposta na retomada do crescimento por meio da valorização do capital fictício opera a partir de demandas fictícias, por onde circulam os contratos, os negócios de papéis e títulos que geram uma determinada expectativa de rentabilidade.

Assim, a dinâmica econômica passa a ser submetida à ação predatória do capital fictício, o que, em tempos cada vez mais curtos, provoca quadros de crise cada vez mais graves, os quais só podem ser superados com a intensificação da ação destrutiva do capital, de maior exploração do trabalho e, consequentemente, do acirramento da barbárie social.

A saída para o colapso econômico e social tem sido orientada por medidas ultraneoliberais, no campo econômico, a exemplo do redirecionamento de recursos públicos para socorrer o mercado financeiro e da retomada das taxas de exploração da mais-valia; e, do ponto de vista ideopolítico, efetivada através de diversas estratégias, coordenadas pelo Estado e suas instituições, mediante as contrarreformas e a regulação política do mercado do trabalho, vide as legislações em vigência no Brasil que instituíram formas brutais de precarização da vida e do trabalho, além do discurso do empreendedorismo, que, na realidade, significa autoexploração do trabalhador.

Como reitera Carcanholo (2011), são medidas como arrocho salarial; retirada de direitos (como forma de reduzir o valor da força de trabalho); prolongamento da jornada ou intensidade do trabalho; a busca por novos espaços de acumulação com a intensificação da privatização de serviços; redução dos gastos sociais e reforma do sistema previdenciário, que conduziriam à retomada do crescimento econômico, sob o argumento da necessidade do ajuste e sacrifício da classe trabalhadora.

A exploração do trabalho é potencializada pela dinamização dos recursos das TICs e uso da internet nos processos fabris e seu gerenciamento. A denominada Indústria 4.0 utiliza tecnologia de Inteligência Artificial (AI) e de Internet das Coisas (IoT) com vistas a desenvolver, ao máximo, a automação do processo produtivo mediante uso de diversos recursos que passam a controlar, supervisionar e comandar essa nova fase da indústria no mundo digital (ANTUNES, 2018; 2018a).

Nesse cenário, observa-se a intensificação dos processos produtivos automatizados e do controle digital da logística empresarial, tendo como principais consequências para o mundo do trabalho a expansão do trabalho morto e a ampliação do exército industrial de reserva, conforme afirma Antunes (2018a, p. 91, grifo do autor):

Sua principal consequência para o mundo do trabalho será a ampliação do trabalho morto, tendo o maquinário digital - a "internet das coisas" - como condutor dominante de todo o processo fabril, e a consequente redução do trabalho vivo, por meio da substituição das atividades tradicionais e manuais por ferramentas automatizadas e robotizadas, sob o comando informacional-digital. Como consequência, mais robôs e mais máquinas digitais invadirão definitivamente a produção, tendo as tecnologias da informação e comunicação (TIC) como comandantes dessa nova fase de subsunção real do trabalho ao capital [...]. 
No entanto, vale dizer que a mediação das tecnologias de informação e comunicação nas diferentes esferas produtivas nasce na fábrica e se alastra para toda a sociedade, organizando formas de controle da vida e do trabalho.

No campo da educação, o uso, ampliação e massificação das TICs são disseminados como fatores compatíveis com a dinâmica capitalista contemporânea, que, nessa fase de acumulação, requer a formação de um trabalhador com atributos e habilidades que lhe permitam executar quaisquer atividades ou se inserir em uma variedade de ocupações simples, movendo-se de uma a outra, sempre disponível para realizar diferentes trabalhos.

Embora tais tecnologias já se apresentassem mundialmente como uma tendência desde os anos 1990, sob os auspícios de organismos internacionais - a exemplo do Banco Mundial e da UNESCO — essas instituições apregoavam novas ideias e práticas que deveriam nortear os projetos educacionais, sob o argumento de que as transformações econômicas, políticas, sociais e culturais decorrentes do desenvolvimento do mundo moderno exigiam conteúdos e formatos de aprendizagem flexíveis, compatíveis com a velocidade de tais mudanças. Para tanto, a sociedade do conhecimento ou sociedade da informação caminharia, lado a lado, com as novas configurações do mundo do trabalho e os atualizados mecanismos e estratégias de subordinação do trabalho ao capital.

A partir dos anos 2000, observamos diversas orientações disseminadas pelos mais variados intelectuais orgânicos da burguesia dominante, cujo principal argumento é a afirmação de que os novos modelos educacionais até então vigentes não estariam correspondendo às transformações sociais desencadeadas pela nova dinâmica mundial - marcada por profundas mudanças no campo produtivo e pela globalização.

Nessa perspectiva, evidenciamos a crescente cobrança por maiores níveis de qualificação da classe trabalhadora, os quais, a partir do contexto de reestruturação produtiva do capital, não se restringem ao domínio técnico do trabalho produtivo, mas incluem o desenvolvimento de novas capacidades cognitivas/reflexivas condizentes com as novas demandas da dinâmica (re)produtiva do capital.

Conforme afirma Frigotto (2008), a educação reivindicada é uma educação de qualidade total, ou seja, que proporcione ao indivíduo o desenvolvimento de qualidades (competências) que se enquadrem na lógica do “"cidadão produtivo' prontamente adaptável e que produz em tempo mínimo, qualidade máxima e cuja mercadoria ou serviço se realizem no mercado imediatamente" (FRIGOTTO, 2008, p.523).

Assim, demanda-se uma formação profissional flexível e articulada com o domínio dos novos sistemas tecnológicos ${ }^{2}$ de modo a possibilitar uma constante destruição e reconstrução acelerada das habilidades dos trabalhadores como mais uma estratégia para a recomposição do domínio hegemônico burguês (SAVIANI, 1995) sobre os processos de formação profissional da classe trabalhadora e seu acesso aos conhecimentos e à cultura historicamente desenvolvida pela humanidade.

A partir das análises dos documentos do Banco Mundial (2011), UNESCO (2016) (HADDAD, DRANCOURT 2013; CHENG 2014; AMADIO, OPERTTI, TEDESCO 2014a; SCOTT 2015) e de grupos como Associação Brasileira de Educação a Distância (ABED) e Associação Brasileira de Startups (Abstartups), além de estudos de autores como Christensen, Horn e Staker (2013), e Christensen e Eyring (2014), identificamos três principais tendências ideopolíticas que passam a direcionar as orientações desses organismos em relação às diretrizes das reformas das políticas educacionais a serem implementadas em âmbito mundial.

A primeira tendência diz respeito à centralidade do desenvolvimento de competências individuais e aperfeiçoamento dos processos de aprendizagem como uma nova estratégia de inviabilizar o acesso à educação pela classe trabalhadora.

Nesse sentido, o principal argumento apresentado é que a sociedade está vivenciando um novo desafio: o aumento dos índices de escolaridade e das taxas de alfabetização não está sendo acompanhado pela qualidade dessa formação, o que se reflete na não aquisição dos conhecimentos necessários à inserção dos sujeitos no mercado de trabalho, considerada um dos fatores do desemprego, como podemos evidenciar na citação a seguir:

A nova estratégia centra-se na aprendizagem por uma simples razão: o crescimento, desenvolvimento e redução da pobreza dependem dos conhecimentos e qualificações que as pessoas adquirem, não no número de anos que passaram sentados numa sala de aula. No nível pessoal, embora um diploma possa abrir as portas para um emprego, são as competências do trabalhador que determinam a sua produtividade e capacidade para se adaptar a novas tecnologias e oportunidades. Conhecimento e qualificações contribuem também para que um indivíduo possa ter uma família saudável e instruída, e participe na vida cívica”. (BANCO MUNDIAL, 2011, p. 3). 
Sob essa ótica, a perda de postos de trabalho e a redução quantitativa no número de empregados se constituem em um fato irreversível, e a formação do trabalhador passa a ser reorientada e readaptada para esse novo cenário de incerteza e instabilidade, de modo que ele aprenda a viver em um contexto de não emprego (KRAUSZ, 1999), devendo-se, portanto, não se restringir ao repasse de conhecimentos previamente prontos, pautados no domínio do arsenal técnico-operativo a ser executado pelo trabalhador posteriormente em um determinado campo de atuação.

Outro argumento que visa justificar a defesa da mudança dos processos de aprendizagem a partir de uma redefinição dos sistemas de ensino tradicionais remete à não correspondência entre níveis de formação profissional e maior acesso ao mercado de trabalho, reflexo do processo de reestruturação do mercado de trabalho com a maior inserção dos recursos tecnológicos e informacionais.

Nesse contexto, a UNESCO (2016) questiona os investimentos despendidos para a formação profissional em sistemas de educação tradicionais, sem o devido "retorno" de ascensão social e promoção de bem-estar esperados pelos indivíduos. Reafirma, ainda, a necessidade de serem adotadas, nos processos de formação profissional, formas de aprendizagem mais flexíveis, que possibilitem o desenvolvimento de diversas dimensões de habilidades (transferíveis, cognitivas, alfabetização digital e empreendedorismo) que ultrapassam a dimensão do fazer técnico profissional.

Na verdade, a aceleração do ritmo do desenvolvimento científico e tecnológico dificulta cada vez mais a previsão do surgimento de novas profissões e das necessidades de habilidades a elas associadas. Isso estimula esforços para estabelecer tanto uma educação quanto o desenvolvimento de habilidades profissionais mais reativos, o que inclui maior diversificação e flexibilidade, bem como permite a adaptação de competências a necessidades em rápida transformação. [...] Com frequência, essas competências incluem mais ênfase no que foi chamado, de forma variável, "habilidades transferíveis", "habilidades do século XXI" e "habilidades não cognitivas", incluindo comunicação, alfabetização digital, resolução de problemas, trabalho em equipe e empreendedorismo (UNESCO, 2016, p. 64).

Se no modelo de produção fordista era imposta aos processos educativos a incumbência de preparar os indivíduos nos padrões rígidos de disciplina necessários à organização do trabalho taylorista-fordista, no período de acumulação flexível, sobretudo no atual contexto de intensificação de precarização das condições de trabalho e flexibilização das relações contratuais, o mote orientador passa a ser a disciplina flexível, a necessidade do saber se adaptar e do saber inovar.

A segunda tendência é a que defende a reconfiguração dos sistemas de ensino face às novas reconfigurações no mundo do trabalho e à desresponsabilização estatal com as políticas educacionais públicas.

O discurso da necessidade de reconfiguração dos processos de aprendizagem alinha-se ao argumento que afirma a imprescindibilidade de readequação da gestão e funcionamento dos sistemas de ensino, e sua ênfase recai sobre o questionamento dos atuais modelos institucionais - sejam eles voltados para a educação de ensino básico ou superior. Seriam eles incompatíveis com as novas determinações sociais que emergem a partir dos primeiros dez anos do século XXI — sobretudo a partir da crise de 2008 - , as quais impõem novas estratégias de formação profissional dos sujeitos e redução do financiamento público para as políticas educacionais.

Dentre as principais estratégias a serem adotadas, a UNESCO (HADDAD; DRANCOURT, 2013) apresenta a necessidade de inovar os sistemas universitários a partir da incorporação de novas tecnologias que visam a aperfeiçoar as atividades inerentes à gestão institucional, recursos de Internet, inovação nos processos de ensino-aprendizagem e desenvolvimento de pesquisas, além da diversificação das fontes de financiamento a partir de uma maior interlocução entre empresas privadas e instituições públicas.

O discurso institucional desse organismo aponta para a necessidade de repensar a forma como a aprendizagem é reorganizada diante do atual contexto, no qual se constata a intensa parceria de instituições não governamentais nos processos educativos e na consequente diluição entre o público e o privado. Os argumentos contidos no documento da UNESCO compreendem a educação como um "bem comum", voltada à satisfação de todos os seres humanos e que, portanto, deve ser por todos usufruída. A perspectiva da educação como um "bem público" não seria mais condizente com a realidade atual, implicando, inclusive, em equívocos, ao limitar a apreensão de que a educação, como bem público, estaria restrita à responsabilidade da execução estatal. Na 
realidade, o que está em causa é que a dimensão desse caráter público estaria subsumindo a importância social dos serviços educacionais fornecidos pelos demais setores, particularmente o empresarial e o filantrópico.

Desse modo, defende-se o uso do termo bem comum como o mais adequado para retratar o objetivo em comum inerente aos serviços prestados à população, qualquer que seja o setor a que pertencem. Ao mesmo tempo, a UNESCO (2016, p. 78) invoca que tais princípios devem ser analisados à luz do contexto "cambiante da sociedade, do Estado e do mercado". Aqui, a premissa parece ser a de que esses agentes tenham interesses indiferenciados e conciliáveis.

Outro elemento referente à readequação dos sistemas de gestão e funcionamento institucionais está voltado à necessidade de flexibilização e diversificação institucional, de modo a abranger as múltiplas formas de aprendizagens e de acesso aos conhecimentos disponíveis atualmente. A perspectiva é a de validar/reconhecer os diversos espaços institucionais/formais (ou não) em que a aquisição de conhecimentos pode ocorrer, pois as atuais condições e estruturas de aprendizagem ofertadas pelos tradicionais sistemas de ensino não estariam sendo suficientes para enfrentar os desafios à formação/educação dos indivíduos no século XXI (SCOTT, 2015).

Nesse discurso, destacamos a defesa de um modelo institucional cada vez mais diversificado, flexível, que não se restrinja tão somente aos sistemas de educação presencial tradicionais, mas que possa incluir outras possibilidades, tais como a metodologia de ensino a distância e a valorização de outros espaços, como o próprio lar, o local de trabalho, comunidade, dentre outras possibilidades, como locais de aquisição de conhecimento e efetivação da aprendizagem em moldes flexíveis.

Conforme destaca a Unesco (CARNEIRO, 2007, p. 11 apud SCOTT, 2015, p. 8, tradução nossa): "O local de trabalho, o lar, o ambiente social e o tempo de deslocamento são locais ideais para a aprendizagem flexível"3. Com essas alternativas, a escola institucionalizada perde o monopólio de lugar privilegiado para a aprendizagem.

Os mesmos argumentos são, também, defendidos por Christensen, Horn e Staker (2013) para abordar a terceira tendência que identificamos nos estudos que reivindicam o tempo de aprendizagem flexível. Para os autores, o modelo de instituições de ensino tradicionais está tendencialmente fadado a ser substituído por novos modelos e rearranjos educacionais, cujo surgimento fora possibilitado pelo avanço dos recursos tecnológicos e informacionais. Mesmo que, em certas situações, essa substituição não ocorra de modo absoluto - com o total desaparecimento do modelo tradicional do mercado - há uma tendência de hibridização. No campo educacional, essa tendência se apresenta mediante a possibilidade de utilização, no âmbito do próprio sistema de ensino tradicional, de experiências combinadas de ensino a distância e presencial.

Para Christensen, Horn e Staker (2013), a grande contribuição do processo de hibridização para as instituições de ensino tradicionais seria a liberalização dessas instituições quanto à responsabilidade em repassar/transferir conteúdos e ministrar aulas, promovendo a abertura dessas instituições para atender outras necessidades que até então não poderiam ser priorizadas diante da sobrecarga de demandas e limites institucionais. Para os autores, esse modelo poderia favorecer a promoção de aprendizagens informais, maior interação entre alunos e realização de outras atividades dentro das instituições (seja o campus universitário ou instituições de ensino básico).

Na cena contemporânea, as modalidades de ensino a distância e de ensino híbrido não estão somente articuladas à necessidade de massificação do acesso ao ensino e à sua mercantilização. Mais do que isso, elas estão sendo impostas como uma estratégia pedagógica necessária à formação de um novo perfil profissional, ou, em outros termos, à construção de um trabalhador de novo tipo para o capital.

Aqui se atualiza a noção de empregabilidade — comumente utilizada nas contrarreformas educacionais dos anos 1990 - , para a trabalhabilidade, referência utilizada nas práticas de coaching empresarial e que significa o novo nos processos formativos. Nessa perspectiva, o ensino torna-se mais personalizado a partir da criação de trilhas de aprendizado mais individualizadas e criação de cursos rápidos voltados às demandas e tempos individuais. Na conformação desses percursos, tende-se ao apagamento, ou, pelo menos, à minimização da articulação entre conhecimentos e grades curriculares tradicionais.

Os esforços de análise de Christensen e Eyring (2014) procuram desconstruir a perspectiva de que o elemento central da modalidade de ensino $\mathrm{EaD}$ e do ensino híbrido é apenas a incorporação dos recursos tecnológicos. A estes deve-se articular uma determinada pedagogia de ensino-aprendizagem cujos principais elementos são: uma nova postura de atuação docente e discente; a superação de uma lógica curricular centrada em disciplinas; a valorização de currículos voltados para o desenvolvimento de competências, habilidades e resultados; a incorporação de novos materiais pedagógicos; e a criação de novas tecnologias que visam a 
inovar o processo de aprendizagem, a exemplo do uso de games, tecnologias para simulação, gerenciamento de cursos, material didático-pedagógico, dentre outros.

A expansão e privatização dos sistemas de educação, especialmente no Brasil e nas suas instituições de ensino superior, revelam que a utilização das TICs nos processos educacionais tem sido molecularmente incorporada, criando formas de controle e subordinação do trabalho pedagógico, inclusive sobre os conteúdos da aprendizagem. Trata-se, portanto, de incidir sobre o que se deve aprender em tempos de vigência do pensamento pragmático, utilitarista e de miséria da razão.

\section{O crescimento do mercado de tecnologias educacionais e a inovação dos processos didático- pedagógicos: $o$ transformismo do princípio educativo integral}

A força material que adquirem as perspectivas educacionais mediadas pelas TICs alavanca um mercado dinâmico e lucrativo, capitaneado por grandes conglomerados que operam na esfera financeira, participando do momento dominante do sistema hegemonizado pelo capital fictício.

As EdTechs, acrônimo do termo inglês Educational Technology, são a maior expressão desse processo de ampliação do mercado educacional. Trata-se de empresas que compõem o rol das startups ${ }^{4}$ próprias da educação, cujo foco é a utilização de softwares (programas computacionais) que são utilizados tanto para a aplicação de conhecimento científico de forma prática e para facilitar o processo de aprendizagem dos alunos, quanto para o aprimoramento dos sistemas educacionais, garantindo, conforme a linguagem do ramo empresarial, efetividade e eficácia.

Freitas e Costa (2018) exaltam que, na atualidade, as EdTechs constituem a principal alternativa para o enfrentamento dos problemas que afetam a educação brasileira, dentre eles: falta de estrutura física, baixa qualificação dos professores, espaços institucionais burocráticos e sistemas educacionais arcaicos. Apresentam essas empresas como facilitadoras dos processos de ensino e aprendizagem e potencializadoras de comportamentos adaptativos em face das novas relações sociais produzidas pela expansão das tecnologias.

Desse modo, os processos são invertidos: ao invés do reconhecimento de que é a expansão do uso das TICs que impõe novas formas de agir e pensar no meio social (como uma necessidade premente de reprodução do capital), argumenta-se que são os indivíduos que, a partir da maior convivência com os recursos tecnológicos, mudam sua forma de ser e agir, como num processo de adaptação natural ao meio no qual o próprio mercado se vê também obrigado a inovar suas estratégias de se relacionar com o trabalho e suas tendências contemporâneas.

O mito do fetichismo tecnológico, tratado por Lima (2007), leva a que as problemáticas educacionais sejam compreendidas como um fim em si mesmas, descontextualizando-as das dinâmicas socioeconômica, histórica e política que as produziram. As tecnologias, como resultado da criação do trabalho humano, portadoras de contribuições importantes à humanidade, passam a ser apreendidas a partir de teorias e práticas reducionistas e utilitaristas, principalmente no campo educacional. Parte-se do princípio de que os problemas sobre os quais as tecnologias irão atuar têm suas origens em inoperantes ou antiquadas formas de organização dos processos de ensino-aprendizagem, na ineficácia da gestão, na desqualificação dos professores e, ainda, no desinteresse dos alunos. Todas essas questões seriam passíveis de resolução, mediante propostas inovadoras apresentadas pelos recursos tecnológicos.

As EdTechs reivindicam possuir uma missão social, posto que são protagonistas de processos inovadores e empreendedores para o enfrentamento de questões cujas determinações são históricas e estruturais, mas respondidas com a mediação de máquinas e controles "inteligentes" que, de forma engenhosa, incorporam o saber e a qualificação dos trabalhadores/as da educação, transformando-os em seus apêndices. Ademais, tais empresas têm operado no circuito das finanças, cumprindo a função de aplicar capitais excedentes e gerar uma expectativa de retorno dos seus negócios.

São inúmeros os grupos bancários e agências de financiamento que investem nas denominadas empresas emergentes (startups), dentre as quais destacamos o Fundo Br Startups ${ }^{5}$ e o Cubo Itaú6.

Em notícia publicada no jornal O Estadão, em 06 de fevereiro de 2019, o Fundo Br Startups investiu um montante de $\mathrm{R} \$ 800.000,00$ (oitocentos mil reais) na startup VoA educação. Esta empresa desenvolveu uma tecnologia com base em inteligência artificial, com a finalidade de auxiliar professores na avaliação e desenvolvimento de capacidades socioemocionais de seus alunos. No caso da Cubo Itaú, segundo informações 
colhidas no site da instituição (CUBO ITAÚ), entre suas instituições parceiras encontram-se o Grupo Kroton, Tim, Dasa e BrMalls. Dezenove startups que trabalham com diversas tecnologias constituem o empreendimento. Vale destacar que, com apenas dezoito meses de atuação, a instituição atraiu uma média de $\mathrm{R} \$ 100$ milhões de reais em investimentos. Somente entre janeiro e junho de 2018, as startups que integram o Cubo Itaú obtiveram um faturamento total de $\mathrm{R} \$ 230$ milhões de reais. ${ }^{7}$

É notável o avanço das tecnologias e a participação das EdTechs na conformação de um mercado educacional, especialmente nos processos de aprendizagem. Ao tempo em que garantem inovadores conteúdos didático-pedagógicos, criam novos campos de investimento e, portanto, de acumulação de capitais. Neste período da pandemia da Covid-19, o uso intensivo e a massificação dos recursos tecnológicos na esfera da educação têm sido justificados no sentido de maior democratização do acesso ao conhecimento, garantia de melhor qualidade do ensino e aprendizado, desburocratização no âmbito do gerenciamento de instituições, facilidade e comodidade ao estudar, além da valorização de novos espaços e novas formas de aquisição de conhecimentos.

Os benefícios e as oportunidades desvelados pelo constante desenvolvimento de novas tecnologias são um fato inegável, uma vez que expressam o avanço das forças produtivas de uma sociedade. Contraditoriamente, são apropriados de forma desigual pelas classes em presença, aprofundando ainda mais as estruturas que dão sustentação à dominação burguesa.

\section{Considerações finais}

As reflexões apresentadas neste texto interpelam a discussão sobre as sociabilidades construídas na esteira da utilização e incorporação das TICs no cotidiano e sua funcionalidade para a reprodução da vida social, razão pela qual não podemos perder de vista os interesses e as relações que estão subjacentes ao movimento do capital e das classes dominantes, as quais tomam o campo da educação como laboratório de novas formas de controle e disciplinamento da força de trabalho.

$\mathrm{Na}$ arena mediada pelas TICs, têm sido forjados sujeitos inovadores e empreendedores sob o argumento de que estes possam dinamizar a economia e incidir sobre os problemas práticos da realidade contemporânea. Para isso, faz-se necessária uma formação que corresponda ao atual estágio de desenvolvimento capitalista, cujas principais características são a flexibilidade e a capacidade de conviver em uma conjuntura de incertezas e de trabalho desprotegido.

O acirramento da crise capitalista e o quadro da crise sanitária que se impôs ao mundo a partir de 2020 massificaram a utilização dos recursos das TICs, colocando no centro das atenções as suas potencialidades para reconfigurar os processos educativos da classe trabalhadora, e, portanto, o perfil requerido para sua adequação no mundo do trabalho. A aprendizagem flexível, combinada às características empreendedoras dos/das trabalhadores/as são tendências que vêm se consolidando como uma estratégia político-ideológica, sustentada pela mercantilização da educação e avanço das contrarreformas necessárias que alteram conteúdos e práticas pedagógicas, na tentativa de rebaixar os processos educativos universais e integrais que se propõem à crítica desta sociedade.

No universo da educação, as TICs adquirem um peso significativo na conjuntura. As tendências de incorporação do Ensino Remoto e o trabalho através de plataformas digitais/aplicativos no cotidiano da sociedade são a expressão mais desenvolvida do projeto das classes dominantes para educar seus/suas trabalhadores/as. Cabe dizer que o processo em curso é também endossado pelas iniciativas de ensino a distância nas universidades públicas - através da instituição da Universidade Aberta no seu interior — e o projeto de Lei n. 3261/2015, que visa regulamentar a educação domiciliar no Brasil.

Diante das reflexões desenvolvidas, podemos compreender que a expansão do uso e dos recursos tecnológicos nos processos de formação e qualificação profissional da classe trabalhadora, apesar de se apresentar sob uma face de modernização e ampliação das oportunidades de acesso e aquisição de conhecimentos, evidencia o seu redirecionamento e alinhamento às novas formas de viver impostas pelo capital.

Nesse contexto, ainda que não tenhamos encontrado formas de enfrentamento e resistência concretas às formas precárias e flexíveis que se incorporam aos processos educativos, mediadas pelas tecnologias de comunicação e informação, a produção de um conhecimento crítico e a não naturalização das tendências de legitimar a miséria da razão são as nossas forças para construir uma outra racionalidade. 


\section{Referências}

AMADIO, M.; OPERTTI, R; TEDESCO J. C. Un currículo para el siglo XXI: desafíos, tensiones y cuestiones abiertas. Investigación y Prospectiva en Educación, UNESCO, Paris. [Documentos de Trabajo ERF, N. 9], 2014a.

ANTUNES, R. A vigência (e a vingança) de Marx: o novo proletariado de serviços, valor e intermitência. Revista Margem Esquerda, São Paulo, n. 31, 2018a.

ANTUNES, R. O privilégio da servidão: o novo proletariado de serviços na era digital. 1. ed. São Paulo: Boitempo, 2018.

BANCO MUNDIAL. Estratégia 2020 para a Educação do Grupo Banco Mundial. Resumo Executivo. Aprendizagem para Todos: Investir nos Conhecimentos e Competências das Pessoas para Promover o Desenvolvimento. Washington, DC: Banco Mundial, 2011. CARCANHOLO, M. D. Conteúdo e forma da crise atual do capitalismo: lógica, contradições e possibilidades. Crítica e Sociedade: revista de cultura política, Uberlândia, v. 1, n. 3, 2011.

CHENG, K. Volver a interpretar el aprendizaje. Investigación y Prospectiva en Educación UNESCO, Documentos Temáticos, Hong Kong, 10 set. 2014.

CHRISTENSEN, C.; HORN, M. B.; STAKER, H. Ensino Híbrido: uma Inovação Disruptiva? Uma introdução à teoria dos híbridos. 2013. Disponível em: https://s3.amazonaws.com/porvir/wp-content/uploads/2014/08/PT_Is-K-12-blended-learning-disruptive-Final. pdf. Acesso em: 17 maio 2021.

CHRISTENSEN, C. M.; EYRING, H. J. A universidade inovadora: mudando o DNA do ensino superior de fora para dentro. Tradução de Ayresnede Casarin da Rocha. Porto Alegre: Bookman, 2014.

CUBO ITAÚ. Disponível em: https://cubo.network/. Acesso em: 24 fev. 2019.

FREITAS, T; COSTA J. E. EDTECHS: O futuro da educação. São Paulo: StartSe, 2018 [Ebook].

FRIGOTTO, G. Educação Profissional e capitalismo dependente: o enigma da falta e da sobra de profissionais qualificados. Revista Trabalho, Educação e Saúde, Rio de Janeiro, v. 5, n. 3, p. 521-536, 2008.

HADDAD, G. DRANCOURT, M. La enseñanza superior frente a las conmociones de la época. Investigación y Prospectiva en Educación UNESCO, París. [Documentos de Trabajo ERF, N. 6], 2013.

HARVEY, D. A condição Pós-Moderna. 17. ed. São Paulo: Edições Loyola, 2017.

KRAUSZ, R. R. Trabalhabilidade. São Paulo: Nobel, 1999.

LIMA, K. Contra-reforma na educação superior: de FHC a Lula. São Paulo: Xamã, 2007.

MÉSZÁROS, I. A crise estrutural do capital. São Paulo: Boitempo, 2011.

SAVIANI, D. Escola e Democracia: teorias da educação, curvatura da vara, onze teses sobre educação e política. Campinas, SP: Autores Associados, 1995.

SCOTT, C.L. El futuro del aprendizaje (i) ¿Por qué deben cambiar el contenido y los métodos de aprendizaje en el siglo XXI? Investigación y Prospectiva en Educación UNESCO, Paris. [Documentos de Trabajo ERF, No. 13], 2015. Disponível em: https:// studylib.es/doc/4849911/el-futuro-del-aprendizaje--i---\%C2\%BFpor-qu\%C3\%A9-deben-cambiar-el-. Acesso em: 17 maio 2021.

UNESCO. Repensar a educação: rumo a um bem comum mundial. Brasília, Organização das Nações Unidas para a Educação, a Ciência e a Cultura, 7, Place de Fontenoy, 2016.

\section{Notas}

1 Analisamos os relatórios produzidos pelo Banco Mundial, UNESCO e os estudos divulgados pela Associação Brasileira de Educação a Distância (ABED), pelo Portal Desafios da Educação e pelo Instituto Clayton Christensen, que serão sucintamente apresentados neste artigo.

2 Evidente que isso não se aplica de modo uniforme a todos os trabalhadores. O acesso aos recursos tecnológicos também é perpassado por conflitos e interesses de classe. Ele é, portanto, apropriado de forma desigual e combinada.

3 "El lugar de trabajo, el hogar, el medio social y el propio tiempo de desplazamiento constituyen sitios óptimos para el aprendizaje flexible" (CARNEIRO, 2007, p. 11 apud SCOTT, 2015, p. 8).

4 Conforme definição apresentada pelo site da Associação Brasileira de Startups (Abstartups), startups são empresas compostas por uma equipe multidisciplinar que visa desenvolver produtos e/ou prestar serviços de caráter inovador e que tenha uma alta capacidade de multiplicação de seus produtos e/ou serviços. Para isso, a principal característica dessas empresas é o uso de tecnologias de informação e comunicação e recursos de internet, além de contar com uma equipe profissional relativamente pequena e uma dinâmica de funcionamento flexível, capaz de se adequar rapidamente às novas demandas e variações de mercado.

5 Br Startups é o primeiro fundo multicorporativo de capital somente brasileiro. Foi idealizado pela empresa Microsoft Brasil e conta como principais investidores: a Microsoft do Brasil; Banco Votorantin; Banco do Brasil Seguros; Qualcomm Ventures; Grupo Algar; Monsanto Ventures; ES Ventures e a AgeRio.

6 Lançado em setembro de 2015, ele é o centro de empreendedorismo e tecnologia do Banco Itaú. O objetivo do Cubo Itaú é concentrar, em um único espaço, grandes empreendedores, empresas, investidores, universidades e promover a sua conexão com startups, para discutirem sobre inovação, tecnologia e novos modelos de negócios.

7 Informações obtidas no site Cubo Itaú: https://cubo.network/. Acesso em 24 de fevereiro de 2019. 


\section{Taise Cristina Gomes Clementino de Negreiros}

taisenegreiros@yahoo.com.br

Doutora em Serviço Social pelo Programa de Pós-Graduação em Serviço Social da Universidade Federal de Pernambuco (PPGSS/UFPE)

Professora Adjunta do Departamento de Serviço Social da Universidade de Brasília (UnB)

\section{SER/UNB}

Campus Universitário Darcy Ribeiro, Instituto Central de Ciências (ICC NORTE - Asa Norte)

Brasília - DF/Brasil

CEP: 70910-900

\section{Angela Santana do Amaral}

angelaufpe@yahoo.com.br

Doutora em Serviço Social pelo Programa de Pós Graduação em Serviço Social da Escola de Serviço

Social da Universidade Federal do Rio de Janeiro (PPGSS/ESS/UFRJ)

Professora Associada do Departamento de Serviço Social da Universidade Federal de Pernambuco

\section{DSS/UFPE}

Avenida dos Economistas, S/N, Cidade Universitária

Recife -PE/Brasil

CEP: 50740-580

\section{Agradecimentos}

Agradecemos o apoio financeiro da CAPES pela concessão da

bolsa de estudos para o doutorado.

Agência financiadora

Não se aplica.

Contribuições das autoras

$\mathrm{O}$ artigo foi elaborado, por completo, pelas autoras.

Aprovação por Comitê de Ética

Não se aplica.

Consentimento para publicação

Consentimento das autoras.

\section{Conflito de interesses}

Não há conflito de interesses. 